\section{SMOKING MOTHERS AND ANTENATAL PREDICTIVE FACTORS OF NECROTIZING ENTEROCOLITIS}

\author{
K. Husseini ${ }^{1}$, A. Fillonneau ${ }^{2}$, J. Mcheik ${ }^{3}$, \\ J. Rousseaux ${ }^{1}$, A. Parizel ${ }^{1}$, C. Bremaud ${ }^{4}$ \\ ${ }^{1}$ Neonatal Intensive Care Unit, ${ }^{2}$ Obstetrics, \\ ${ }^{3}$ Pediatric Surgery Department, CHU Poitiers, \\ ${ }^{4}$ Pediatric Intensive Care Unit, Chu Poitiers, \\ Poitiers, France
}

Background: Previous studies did not find association between drug addiction during pregnancy except cocaine and the prevalence of necrotizing enterocolitis (NEC).

Objective: Study antenatal predictive factors of NEC, in monocentric study population, compared to factors currently identified.

Material and methods: We conducted a casecontrol study in a monocentric Neonatal Intensive Care unit from $1^{\text {st }}$ January 2002 to the $31^{\text {st }}$ December 2008. Maternal and fetal clinical characteristics were compared between 49 NEC cases, stages II or more of Bell classification (mean $\mathrm{GA} \pm \mathrm{SD}=29.3 \pm 2.8 \mathrm{wks}$; birth weight $=1218 \pm 465 \mathrm{~g}$ ) matched for gestational age at birth to 98 control newborns $(29.6 \pm 2,8$ wks; $1301 \pm 504 \mathrm{~g}$ ). significant anténatal predictive factors were adjusted to post natal predictive factors of NEC identified in previous studies. Postnatal data were assessed in a representative sub population of 23 NEC cases (29.2 $\pm 2.7 \mathrm{wks} ; 1321 \pm 547 \mathrm{~g})$ and 46 control newborns $(28.7 \pm 2.7$ wks; $1255 \pm 493 \mathrm{~g})$.

Results: NEC is associated with more maternal smoking ( $17 / 47$ vs $20 / 97, p=0.045)$, lower socioeconomic conditions (19/45 vs $21 / 94, p=0.026)$ and single dose of antenatal bethamethasone (11/44 vs $7 / 98, p=0.008)$. Multivariate analysis identified two predictive factors of NEC: 1) maternal smoking as a predictive factor of NEC (odd ratio 0.34; IC 95\% [0.14-0.82], $\mathrm{p}=0.016$ ) dependant of socio economic conditions, ductus arteriosus and respiratory pathology. 2) Single dose of antenatal bethamethasone was a predictive factor (odd ratio 0.22; [0.06-0.72], $p=0.013$ ) dependent of neonatal respiratory pathology.

Conclusion: Smoking and single dose of bethamethasone was identified in our study as independent antenatal predictive factor of NEC.

\section{COMPARISON OF MOLECULAR MUTATIONS OF G6PD GENE BETWEEN ICTERIC AND NON ICTERIC NEONATES}

\author{
Y. Zahed Pasha, M. Ahmadpour Kacho, \\ H. Akhavan Niaky, R. Farhadi
}

Babol University of Medical Sciences, Babol, Iran

Objective: Jaundice is a common disorder in neonates and G6PD deficiency could result in kernicterus. The aim of This study was to compare of G6PD mutation in icteric and non icteric neonates.

Methods: This case-control study was done in 50 icteric neonates with G6PD deficiency that needed phototherapy or exchange were selected as case group and 50 non icteric neonates with G6PD deficiency that were admitted to NICU and newborn ward with non icteric etiology were selected as control group.. 2 cc peripheral blood samples were collected in EDTA tube after obtaining parent consent.. G6PD deficiency was diagnosed with FST (Floorescent Spot Test) and billirubin was measured with DSA method. In first stept, all samples were evaluated for Mediterranean mutation and then negative samples were tested for Chatham mutation and finally all remaining samples were tested for Cosenza mutation.

Findings: In non icteric group 54\% were Mediterranean, 18\% Chatham, 28\% Cosenza negative and in icteric group 56\% were Mediterranean, 32\% Chatham, 12\% Cosenza negative and the distribution of Mediterranean and Chatham mutations were not significantly different between two groups $(p>0.05)$ and distribution of rare mutations (Cosenza negative) was significantly different between icteric and non icteric group $(p<$ 0.05). Exchange transfusion in neonates with chatham mutation was needed significantly less than photothrapy $(p<0.05)$.

Conclusion: Mediterranean mutation was the most frequent mutation in icteric and non icteric neonates of our region. but rare mutations (Cosenza negative) were more prevalent in non icteric group. Need to exchange transfusion was less in chatham mutation. 